\title{
Pengaruh Overall Heat Loss Coefficient Terhadap Hasil Output solar still
}

\author{
Regita Septia Cahyani ${ }^{1 *}$, Dan Mugisidi ${ }^{1}$, Rifky $^{1}$, Oktarina Heriyani $^{2}$ \\ ${ }^{1}$ Program Studi Teknik Mesin, ${ }^{2}$ Program Studi Teknik Elektro, Fakultas Teknik \\ Universitas Muhammadiyah Prof. DR. HAMKA \\ Jl. Tanah Merdeka no. 6 Rambutan Ciracas Jakarta Timur DKI Jakarta 13830 \\ Telp. +62-21-87782739 Fax. +62-21-7782739 \\ *E-mail: regitaseptia82@gmail.com
}

\begin{abstract}
Abstrak - Penelitian ini bertujuan untuk mengetahui pengaruh koefisien kehilangan panas keseluruhan terhadap hasil output yang terjadi pada solar still. Penelitian ini menggunakan material stainless still tebal 1,6 mm dan kaca penutup tebal 3mm dengan kemiringan terhadap alat solar still $30^{\circ}$. Pengujian dilakukan mulai pukul 08.00 WIB sampai 17.00 WIB selama 3 hari, dengan beberapa parameter yang di ukur seperti suhu kaca bawah $\left(T_{g i}\right)$, suhu air $\left(T_{w}\right)$, kecepatan angin $(v)$, intensitas radiasi matahari $\left(I(t)_{s}\right)$ yang terdapat dalam sistem alat solar still. Dari hasil pengujian yang dilakukan overall heat loss coefficient tertinggi yaitu sebesar $50,7 \mathrm{~W} / \mathrm{m}^{2}$.K. Semakin tinggi coefficient top heat loss sangat mempengaruhi coefficient heat loss overall sehingga hasil output tidak mengalami kenaikan.
\end{abstract}

Kata kunci: solar still, coefficient heat loss, produktivitas.

\section{Pendahuluan}

Kegunaan air tidak akan terlepas dari kehidupan makhluk hidup di muka bumi ini, karena air merupakan salah satu unsur utama yang merupakan kebutuhan pokok seluruh makhluk hidup. Beberapa sumber air yang tersedia untuk penduduk Indonesia sebagian besar menggunakan air permukaan terutama air sungai dan air sumur. Namun, tidak semua daerah mempunyai sumber air yang baik. Sumber air yang secara kuantitas tidak terbatas adalah air laut. Akan tetapi air laut mengandung kadar garam atau Total Dissolved Solid (TDS) sangat tinggi sehingga diperlukan pengolahan lebih lanjut (Astuti, 2016). Sehingga untuk mendapatkan air bersih perlu adanya pemrosesan atau pengolahan air laut menjadi air tawar. Salah satu solusi untuk mengatasi hal tersebut, maka teknologi seperti desalinasi merupakan pemilihan yang tepat.

Distilasi merupakan salah satu cara yang efektif untuk menghasilkan air bersih yang terbebas dari senyawa maupun unsur lain, selain $\mathrm{H}_{2} \mathrm{O}$. Pada proses distilasi, yang dimanfaatkan atau digunakan hanya air hasil kondensasi, sedangkan senyawa atau unsur lainnya akan mengendap.

Upaya penggunaan energi matahari sebagai alternatif merupakan upaya yang perlu didukung, dengan memanfaatkan sinar matahari sebagai sumber panas untuk memanaskan air laut di dalam proses desalinasi. Hal ini sesuai dengan prinsip bahwa dalam mengembangkan sistem-sistem energi harus dapat memproduksi energi dengan biaya murah serta tidak mengakibatkan dampak lingkungan (Arismunandar \& Wiranto, 1995) Dengan memanfaatkan sinar matahari sebagai sumber panas untuk memanaskan air laut di dalam proses desalinasi.

Pada sistem desalinasi matahari banyak pengamatan tentang desain, kinerja dan keterbatasan produksi air bersih. Output desalinasi mungkin dipengaruhi oleh banyak faktor termasuk kedalaman air laut, kebocoran uap, isolasi termal, kemiringan penutup (Zarzoum, Zhani, \& Bacha, 2016). Oleh karena itu, perhitungan koefisien heatloss overall dari proses distilasi air laut sangat penting. Untuk mengetahui bagaimana pengaruh akibat kehilangan panas dari sistem desalinasi bagi hasil output.

\section{Dasar Teori}

\subsection{Distilasi}

Distilasi adalah proses pemisahan garam dan mineral lainnya dari air laut dengan cara pemanasan guna mendapatkan air bersih (Bara, Mesin, \& Cendana, 2016). Distilasi sangat berguna untuk konversi air laut menjadi air tawar. Konversi air laut menjadi air tawar dapat dilakukan dengan teknik distilasi panas buatan, solar destillation (distilasi tenaga surya), osmosis, dan lain-lain (Effendi, Arifin, \& Hasbi, 2012) Proses ini dimanfaatkan untuk mendapatkan air yang dapat dikonsumsi oleh makhluk hidup. Ketika air laut didihkan, garam akan terlarut dan air akan menguap. Air yang menguap akan menghasilkan uap yang dapat berubah fasa ketika temperatur menurun. Perubahan fasa yang terjadi adalah 
kondensasi yang dapat merubah uap menjadi air kembali (Dewantara, Suyitno, \& Lesmana, 2018).

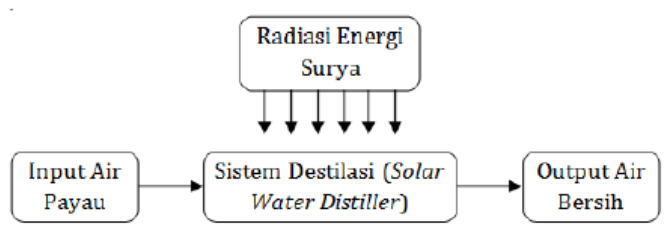

Gambar 2. 1 Proses kerja sistem distilasi tenaga surya (Handayani, Nugroho, \& Fitri, 2014)

\subsection{Perpindahan Panas}

Perpindahan panas (heat transfer) ialah ilmu untuk meramalkan perpindahan energi yang terjadi karena adanya perbedaan suhu di antara benda atau material (Holman, 1995). Perpindahan panas dalam solar still masih dianggap proses perpindahan panas sementara karena variasi suhu atau fluks panas sehubungan dengan waktu.

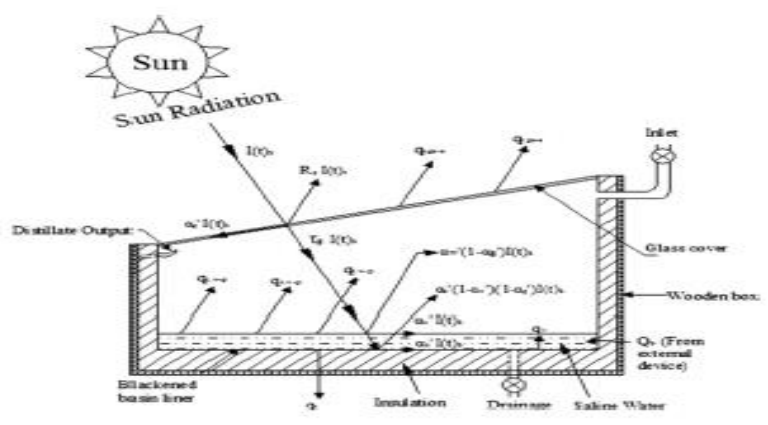

Gambar 2. 2 Skema perpindahan panas pada solar still konvensional (Elango, Gunasekaran, \& Sampathkumaran, 2015)

Proses perpindahan panas dalam solar still dapat digolongkan secara luas dalam proses perpindahan panas internal dan eksternal berdasarkan aliran energi masuk dan keluar dari ruang tertutup.

2.2.1 Perpindahan panas internal didalam solar still yang terjadi antara massa air dengan bagian dalam kaca penutup yaitu konveksi, radiasi dan evaporasi

a. Konveksi

Udara yang mengalir di suatu permukaan bagian atas pada sebuah alat basin type solar still, dipanasi secara konveksi yakni konveksi alamiah (Holman, 1995)

Laju perpindahan panas konveksi di dalam solar still dapat dinyatakan:

b. Radiasi $\quad \mathrm{q}_{\mathrm{c}, \mathrm{w}-\mathrm{gi}}=\mathrm{h}_{\mathrm{c}, \mathrm{w} \text {-gi }}\left(\mathrm{T}_{\mathrm{w}}-\mathrm{T}_{\mathrm{gi}}\right)$

Berlainan dengan mekanisme konduksi dan konveksi, dimana perpindahan energi terjadi melalui bahan perantara, kalor juga dapat berpindah melalui daerah-daerah hampa.

Laju perpindahan panas radiasi di dalam solar still dapat dinyatakan:

$\mathrm{q}_{\mathrm{r}, \mathrm{w}-\mathrm{gi}}=\mathrm{h}_{\mathrm{r}, \mathrm{w}-\mathrm{gi}}\left(\mathrm{T}_{\mathrm{w}}-\mathrm{T}_{\mathrm{gi}}\right)$

Dalam proses distilasi pada bak penampung atau kolam diisi dengan air yang akan diuapkan dan terkena radiasi. Selama penguapan melebihi curah hujan, konsentrasinya akan meningkat seiring waktu (Jhon \& Beckman, 2013).

Laju perpindahan panas penguapan antara massa air dan kaca bagian dalam dapat dinyatakan:

$$
\mathrm{q}_{\mathrm{e}, \mathrm{w}-\mathrm{gi}}=\mathrm{h}_{\mathrm{e}, \mathrm{w}-\mathrm{gi}}\left(\mathrm{T}_{\mathrm{w}}-\mathrm{T}_{\mathrm{gi}}\right)
$$

2.2.2 Perpindahan panas eksternal terdiri dari proses konduksi, konveksi, dan radiasi yang independen satu sama lain. Dianggap sebagai hilangnya energi panas dari matahari hingga atmosfer (Elango et al., 2015)

a. Konveksi

Kehilangan panas konveksi dari kaca yang menutupi permukaan luar solar still hingga atmosfer, sebagai berikut:

b. Radiasi $\quad \mathrm{q}_{\mathrm{c}, \mathrm{go}-\mathrm{a}}=\mathrm{h}_{\mathrm{c}, \mathrm{go}-\mathrm{a}}\left(\mathrm{T}_{\mathrm{go}}-\mathrm{T}_{\mathrm{a}}\right)$

Kehilangan panas radiasi dari kaca menutupi permukaan luar solar still sampai ke sekitarnya, sebagai berikut:

$$
\mathrm{q}_{\mathrm{r}, \mathrm{go}-\mathrm{a}}=\mathrm{h}_{\mathrm{r}, \mathrm{go}-\mathrm{a}}\left(\mathrm{T}_{\mathrm{go}}-\mathrm{T}_{\mathrm{a}}\right)
$$

Proses perpindahan panas tidak semuanya dapat diubah menjadi energi lain, dan pada kolektor surya terjadi kerugian panas. Kerugian panas ini terjadi pada bagian atas, bagian bawah, dan bagian samping (Ully \& Pabiban, 2017)

a. Koefisien kehilangan panas bagian atas keseluruhan dari massa air ke atmosfer melalui penutup kaca dinyatakan sebagai berikut:

$$
\mathrm{U}_{\mathrm{t}}=\frac{h_{t, w-g i} U_{t, g i-a}}{h_{t, w-g i}+U_{t, g i-a}}
$$

b. Koefisien kehilangan panas bagian bawah keseluruhan dari massa air ke atmosfer dinyatakan sebagai berikut:

$$
\mathrm{U}_{\mathrm{b}}=\frac{h_{w} h_{b}}{h_{w}+h_{b}}
$$

c. Koefisien kehilangan panas bagian samping keseluruhan dari massa air ke atmosfer dinyatakan sebagai berikut:

$$
\mathrm{U}_{\mathrm{ss}}=\left(\frac{A_{s s}}{A_{b}}\right) \mathrm{U}_{\mathrm{b}}
$$

d. Koefisien kehilangan panas eksternal secara keseluruhan dari massa air ke atmosfer melalui bagian atas, bagian bawah dan bagian samping solar still dinyatakan sebagai berikut:

$$
\mathrm{U}_{\mathrm{LS}}=\mathrm{U}_{\mathrm{t}}+\mathrm{U}_{\mathrm{bs}}
$$

\section{Metodologi Penelitian}

\subsection{Tempat dan Waktu Penelitian}

Penelitian ini dilaksanakan pada bulan Agustus sampai dengan bulan September 2018. Tempat penelitian dilaksanakan di Lantai 5 Fakultas Teknik Universitas Muhammadiyah Prof. DR. HAMKA.

\subsection{Desain Penelitian (Rancangan Penelitian)}




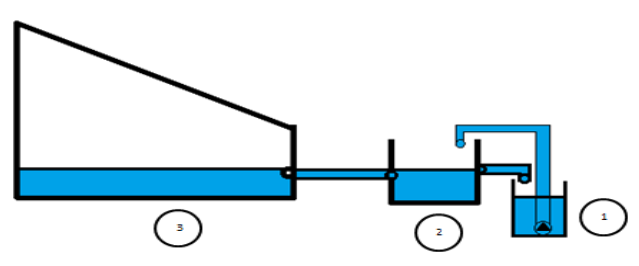

Gambar 3. 1 Skema Sirkulasi Air

Pada Gambar 3.1 menjelaskan sirkulasi air laut dari bak utama (1) dipompakan ke bak nomor (2) yang sudah ditentukan ketinggian airnya sesuai dengan air di dalam solar still (3). Apabila air di bak nomor 2 sudah melewati lubang batas yang sudah ditentukan maka air akan keluar melalui lubang over flow kembali menuju ke bak utama.

3.3 Alat dan Bahan

3.3.1 Alat

1 Termometer

2 Timbangan

3 Anemometer

4 Solar power meter

5 Stopwatch

3.3.2 Bahan

1 Air laut

2 Stainless still dengan ketebalan 1,6 mm

3 Kaca dengan ketebalan $3 \mathrm{~mm}$

3.4 Diagram Alir Penelitian

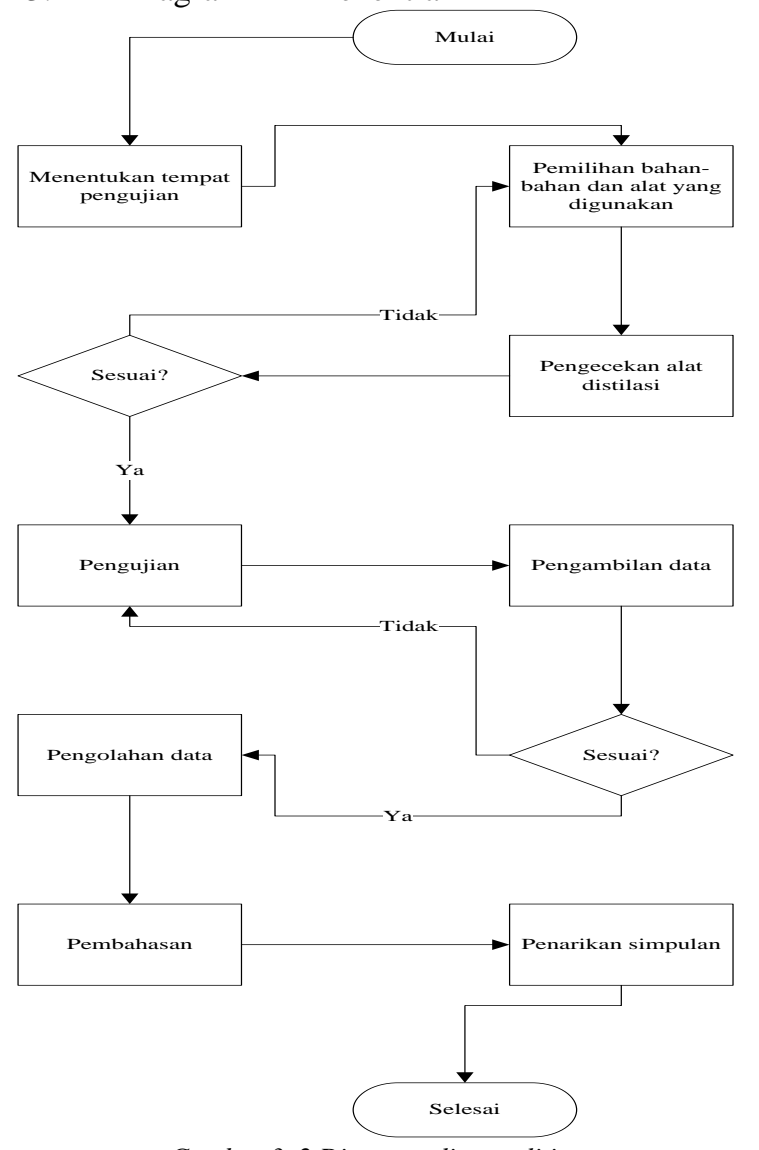

Gambar 3. 2 Diagram alir penelitian
4. Temuan dan Pembahasan

4.1 Temuan Penelitian

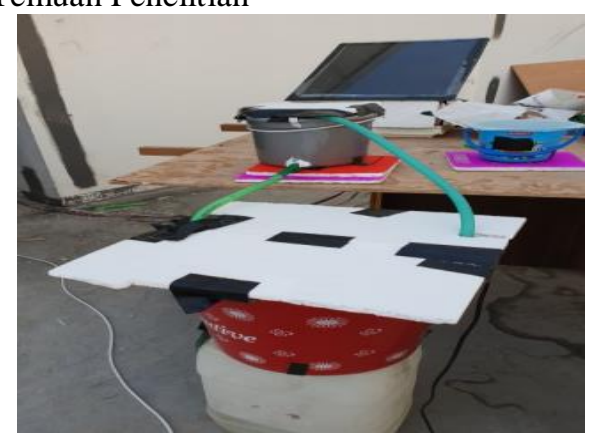

Gambar 4. 1 Rangkaian pengujian sistem

Pada Gambar 4.1 dijelaskan bahwa sistem pengujian solar still bak utama ukuran besar yang berisi air laut di pompa air laut mengalir melewati selang mengisi bak yang ukurannya lebih kecil. Bak ukuran kecil dibuat lubang sisi belakang bak dengan tinggi $1,5 \mathrm{~cm}$ dengan tujuan air yang melebihi batas lubang dibuat overflow air akan terbuang keluar melewati selang menuju bak utama untuk menjaga ketinggian air sama dengan yang ada didalam solar still. Bak ukuran kecil sisi depan dibuat lubang yang terhubung lebih pendek dibandingkan lubang overflow dengan tujuan agar air laut mengalir melalui selang yang menghubungkan kedalam solar still (air input). Air laut terus bersirkulasi.

Tabel 1 Hasil rata-rata

\begin{tabular}{|c|c|c|c|}
\hline Tanggal Pengujian & $\begin{array}{c}\mathrm{T}_{\mathrm{gi}}( \\
\left.{ }^{\circ} \mathrm{C}\right)\end{array}$ & $\begin{array}{c}\mathrm{T}_{\mathrm{w}}( \\
\left.{ }^{\circ} \mathrm{C}\right)\end{array}$ & $\mathrm{v}(\mathrm{m} / \mathrm{s})$ \\
\hline $23-08-2018$ & 45,1 & 48,1 & 0,6 \\
\hline $29-08-2018$ & 43,8 & 48,0 & 0,6 \\
\hline $1-09-2018$ & 52,3 & 52,7 & 1,1 \\
\hline
\end{tabular}

4.2

Pembahasan

Grafik hari 1

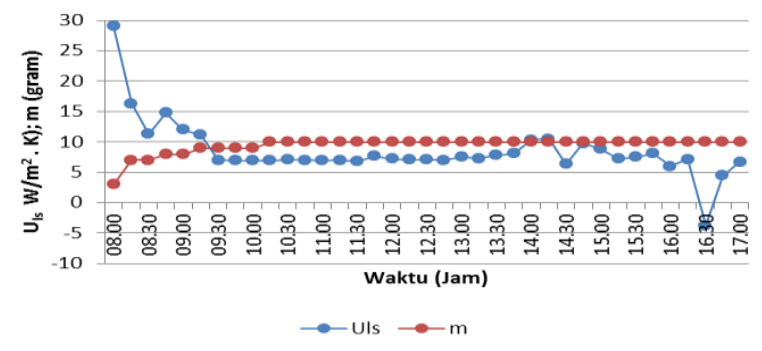

Grafik 4. 2 Grafik kehilangan panas dari massa air ke atmosfer Grafik hari 2

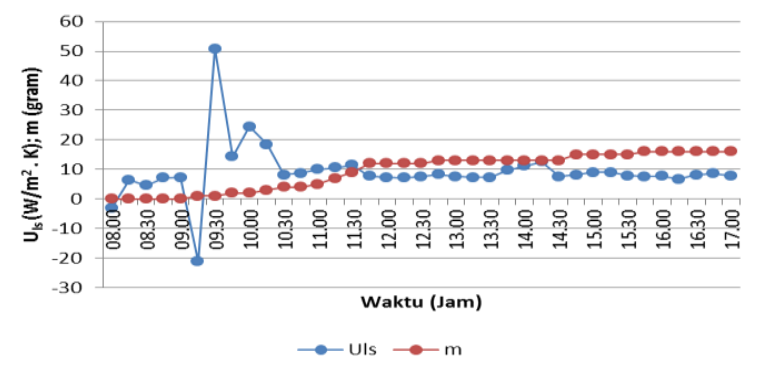

Grafik 4. 3 Grafik kehilangan panas dari massa air ke atmosfer 
Grafik hari 3

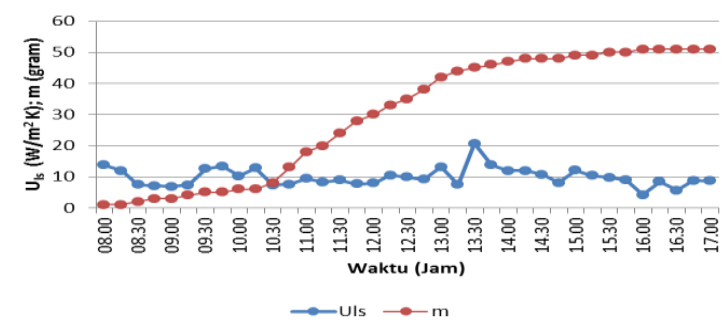

Grafik 4. 4 Grafik kehilangan panas dari massa air ke atmosfer

Pada Gambar 4.2, Gambar 4.3, dan Gambar 4.4 menjelaskan bahwa hasil teoritis kehilangan panas keseluruhan solar still disebabkan kehilangan panas bagian atas $\left(\mathrm{U}_{\mathrm{t}}\right)$ pada saat matahari meradiasikan panasnya ke solar still sebagian panas itu hilang terbawa angin, sebagian panas masuk menembus kaca menkonduksikan panas merambat ke plat. Sebelum memanaskan air di dalam basin terjadi terjadi konveksi panas dari plat menuju basin mengalami kehilangan panas pada bagian sisi $\left(\mathrm{U}_{\mathrm{ss}}\right)$ dan pada bagian bawah dari plat basin akibat pemakaian styrofoam sebagai bahan insulasi yang tidak merekat pada plat solar still. Menurut hasil grafik pengaruh kehilangan panas secara keseluruhan terhadap hasil output proses distilasi bahwa semakin tinggi kenaikan pada grafik kehilangan panas hasil outpt tidak mengalami kenaikan.

\section{Simpulan}

1. Penelitian ini bertujuan untuk mengetahui pengaruh kefisien kehilangan panas keseluruhan terhadap hasil output yang terjadi pada solar still.

2. Pada perhitungan kehilangan panas keseluruhan (bagian atas, bawah, dan samping) nilai tertinggi selama 3 hari pengujian sebesar $50,7 \mathrm{~W} / \mathrm{m}^{2} . \mathrm{K}$. Kenaikan hasil koefisien kehilangan panas keseluruhan dipengaruhi karena adanya angin yang melewati bagian atas kaca penutup yang membuat kehilangan panas pada bagian atas $\left(\mathrm{U}_{\mathrm{t}}\right)$ sangat tinggi.

3. Semakin tinggi kehilangan panas yang dihasilkan, hasil output air dalam proses distilasi tidak mengalami kenaikan.

\section{Kepustakaan}

[1] Arismunandar, \& Wiranto. (1995). Teknologi Rekayasa Surya. Jakarta: PT Pradnya Paramita.

[2] Astuti, U. P. (2016). ATAP DESALINASI SEBAGAI SOLUSI PEMENUHAN. Journal of Research and Technology, 2(2).

[3] Bara, D. A., Mesin, J. T., \& Cendana, U. N. (2016). Pengaruh Tebal Kaca Penutup terhadap Efisiensi Kolektor Surya Pelat Gelombang Tipe V pada Proses Destilasi Air Laut, 3(2), 1-10.

[4] Dewantara, I. G. Y., Suyitno, B. M., \& Lesmana, I. G. E. (2018) Desalinasi Air Laut Berbasis Energi Surya Sebagai Alternatif Penyediaan Air Bersih, 7(1), 3-6.

[5] Effendi, M. S., Arifin, M. K., \& Hasbi, M. (2012). Pengaruh Penggunaan Preheater pada Basin Type Solar Still dengan Tipe Kaca Penutup Miring terhadap Efisiensi. Spektrum Industri, 10(2), 108-199.

[6] Elango, C., Gunasekaran, N., \& Sampathkumaran, K. (2015). Thermal Models of Solar Still-A Comprehensive Review. Renewable and Sustainable Energy Reviews, 47, 856-911.

[7] Handayani, N., Nugroho, T. F., \& Fitri, S. P. (2014). Analisa Kinerja Termal Solar Apparatus Panel pada Alat Destilasi Air Payau dengan Sistem Evaporasi Uap Tenaga Matahari Menggunakan CFD. Jurnal Teknik POMITS, 3(2).

[8] Holman, J. . (1995). Perpindahan Kalor. Jakarta: Erlangga.

[9] Jhon, A. D., \& Beckman, W. A. (2013). Solar Energineering of Thermal Process. Canada: Wiley.

[10] Ully, D. N., \& Pabiban, D. (2017). PENGARUH PENYERAPAN RADIASI SURYA PADA ME- DIA TIPE KOTAK DAN BERGELOMBANG BERBAHAN DASAR STAINLESS STEEL TERHADAP KEMAMPUAN DESTILASI AIR PAYAU DI PESISIR PANTAI SEBA. Jurnal Ilmiah Flash, 3(2), 115-121.

[11] Zarzoum, K., Zhani, K., \& Bacha, H. Ben. (2016). Numerical study of a water distillation system using solar energy $\uparrow$. Journal of Mechanical Science and Technology, 30(2), 889-890. https://doi.org/10.1007/s12206-016-0143-4 